\title{
Empresariamiento de la sociedad y el gobierno de la infancia pobre
}

\section{Artículos temáticos $\quad \begin{aligned} & \text { de Educación, N. }{ }^{\circ} 65 . \\ & \text { Segundo semestre de 2013, }\end{aligned}$ Bogotá, Colombia.}

\author{
//Management of poor children \\ by society and government
}

\section{//Empresariamento da sociedade \\ e governo da infância pobre}

\section{Sylvio Gadelha*}

\begin{abstract}
Professor do Departamento de Fundamentos da Educação da Faculdade de Educação da Universidade Federal do Ceará FACED-UFC; Professor do Programa de Pós-Graduação em Educação Brasileira da FACED-UFC; Coordenador, neste Programa, do Eixo de Pesquisas "Filosofias da Diferença, Antropologia e Educação"; Professor do Programa de Pós-Graduação em Artes do ICA-UFC. E-mail: sylviogadelha@uol.com.br
\end{abstract}

\section{Resumen}

Tomando distancia de ciertas perspectivas de la historia de las mentalidades y otros enfoques que presuponen la existencia de un único modelo de infancia, correspondiente a la familia nuclear pequeño burguesa, el texto, siguiendo a Donzelot (1980) y en una orientación marcadamente foucaultiana, considera más acertado hablar de que la modernidad posibilitó la construcción más o menos simultánea de dos distintas concepciones de infancia: de una lado, la "pequeño burguesa", y de otro, la infancia pobre u obrera.

Partiendo de esta diferenciación, el texto se propone explorar las siguientes ideas: 1) en nuestro presente, tanto el gobierno como el control de las subjetividades y de las conductas infantiles, ya sea las referidas a la infancia pobre (excluida) o a la infancia de origen pequeño burgués, son efectuados mediante la estrategia de un empresariamiento generalizado de la sociedad y de la educación; 2) En el caso de la infancia pobre (excluida), su gobierno y su control se ejercen primordialmente a través de políticas, programas y/o proyectos asistencialistas, socioeducativos y culturales de orientación eminentemente biopolítica, los cuáles funcionan en estrecha sintonía con esa tendencia a un empresariameniento generalizado de la sociedad y la educación.

\section{Abstract}

Getting distance from certain perspectives of history of mentalities and other approaches that assume the existence of a unique model of childhood, corresponding to the petit bourgeois nuclear family, this text, following Donzelot (1980) and a makeable Foucauldian guidance considers more accurate to speak of modernity that allowed the simultaneous construction of two different conceptions of childhood: on one hand, "petit bourgeois" and on the other hand, poor or working childhood.

Based on this differentiation, this text aims to explore the following ideas: 1 ) in our present, both the government and control of subjectivity and child behaviors (whether those related to poor children (excluded) or childhood petit bourgeois origin) are made through the strategy of widespread entrepreneurialism of society and education; 2) in the case of poor children (excluded), its government and control is primarily exerted through policies, helping programs or socio-cultural or socio-educational projects orientated eminently by biopolitics,

\section{Palabras Clave}

Gobierno de la infancia, empresariamiento, gubernamentalidad neoliberal.

\section{Keywords}

Governing childhood, management, neoliberal governmentality.

\section{Palavras chave}

Governo da infância, empresariamento, governamentalidade neoliberal. 
which work in close harmony with the trend to widespread entrepreneurialism of society and education.

\section{Resumo}

Afastando-se de alguns abordagens da história das mentalidades e outros enfoques que pressupõem a existência de um único modelo de infância aquela correspondente à família nuclear pequeno-burguesa, o texto, seguindo Donzelot (1980) e assumindo uma orientação marcadamente foucaultiana, considera mais acertado falar que a modernidade deu ensejo à construção mais ou menos simultânea de dois distintas concepções de infância: de um lado, uma infância "pequeno-burguesa" e, de outro, a infância pobre ou operária.

Partindo dessa diferenciação, o escrito propõe-se explorar as seguintes ideias: 1) no nosso presente, tanto o governo quanto o controle das subjetividades e das condutas infantis, seja das referentes à infância pobre (infância excluída), seja das referentes à infância de origem pequeno-burguesa, são efetuados mediante a estratégia de um empresariamento generalizado da sociedade e da educação; 2) No caso da infância pobre (excluída) seu governo e seu controle se exercitam primordialmente através de políticas, programas e/ou projetos assistenciais, socioeducativos e culturais de orientação eminentemente biopolítica, os quais funcionam em estreita sintonia com essa tendência a um empresariamento generalizado da sociedade e da educação.

\section{Introdução: infância ou infâncias?}

O tema por mim proposto originalmente à comissão organizadora do "Il Colóquio Nacional Michel Foucault: Governo da infância", e anunciado em sua programação, foi "Empresariamento da sociedade e governo das infâncias". Todavia, naquela ocasião, por problemas alheios ao evento, sobretudo por questões de tempo, decidi reduzir minha apresentação, limitando-me a abordar apenas o caso do governo da infância pobre. A despeito da mudança no título, todavia, creio que vale a pena esclarecer brevemente os motivos pelos quais minha intenção, a princípio, era a de referir-me ao governo "das infâncias", no plural.

O primeiro deles foi o de buscar distanciar-me de abordagens analíticas que seguem, em maior ou menor medida, aquela formulada por Phillipe Ariès (1981) no seu clássico História social da criança e da família. Ou seja, por um lado, abordagens mais ou menos sintonizadas com uma história das mentalidades, as quais não teriam logrado êxito, segundo Jacques Donzelot (1980, p. 12), em escapar ao que este autor chamou de "clivagem infinita entre política e psicologia". Por outro lado, abordagens que, além disso, trariam como pressuposto a existência de um único modelo (representação ou imagem) de infância, correspondente à família nuclear pequeno-burguesa, modelo este que teria 
se expandido progressivamente, em círculos concêntricos, pela superfície das sociedades ocidentais modernas, até recobri-las por inteiro, à maneira de um universal abstrato. ${ }^{1}$ De todo modo, diversamente dessa perspectiva, seguindo Donzelot (1980) e, indiretamente, assumindo uma orientação marcadamente foucaultiana, considerava e continuo considerando mais acertado falar que a modernidade deu ensejo à construção mais ou menos simultânea de duas distintas concepções de infância: de um lado, uma infância "pequeno-burguesa", por assim dizer, que evoca pureza, fragilidade, inocência e que demanda cuidados especiais, na medida em que remete a um ser em "condições peculiares de desenvolvimento", como se diz de alguns anos para cá; de outro, uma infância que emerge como o negativo dessa primeira, infância proveniente das famílias pobres e operárias, e que evoca, por seu turno, "carência", "deficiência", "diferença", ao mesmo tempo em que é caracterizada pelos signos do abandono, do desvio, da patologia social, do risco (cf. Martins, 2009), da periculosidade e da delinqüência. Não é sem razão que muitos anos atrás me deparei com uma curiosa

1 Para uma ideia de outros fatores problemáticos relacionados a análises históricas, sociológicas, antropológicas e psicológicas que parecem pressupor a existência de um único modelo, representação ou imagem de infância, cf. Kuhlmann Jr. (2007), especialmente o Capítulo I (Infância, história e educação), pp. 15-38; Sarmento (2009); Gomes (2009); Cohn (2005); Dornelles (2005); Bujes (2002); Buckingham (2007); Rizzini e Pilotti (2009). manchete de jornal, cuja referência infelizmente me escapou, mas que, em todo caso, dizia o seguinte: "Criança é assaltada por menor". Com efeito, crianças não assaltam crianças; se bem que, ultimamente, cometem bullying, conforme asseveram os especialistas do campo "médico-psi".

Mas há ainda um segundo motivo, correlato ao primeiro, para que eu preferisse falar em governo "das infâncias", no plural. Ele diz respeito, ainda segundo Donzelot (1980), ao fato de que as estratégias, mecanismos, procedimentos e técnicas implicados às produções desses dois tipos de subjetividades infantis diferiram historicamente, conforme se tratasse da infância pequeno-burguesa ou da infância das classes pobres e/ou operárias. Assim, segundo Donzelot (1980), ao passo que a gestão dos problemas concernentes à infância pequeno-burguesa requereu uma intervenção pautada por uma medicina e uma economia domésticas, a gestão dos problemas relacionados à infância pobre (ou operária), por sua vez, demandou uma intervenção pautada por uma economia social. Ao passo que a primeira dessas infâncias tornouse objeto de uma liberdade vigiada (ou liberação protegida), a segunda, por sua vez, tornou-se objeto de programas biopolíticos médico-assistenciais, tais como os instituídos pelos higienistas e reformadores sociais nos estertores do século XIX e nas primeiras décadas do século XX. Decerto que alguns mecanismos 
e táticas similares de intervenção foram utilizados transversalmente tanto num quanto noutro desses dois segmentos populacionais infantis, mas isso não deve obscurecer as diferentes estratégias e procedimentos que presidiram as intervenções em cada um deles.

De qualquer modo, para os meus propósitos, importa tentar seguir e explorar as seguintes ideias: em primeiro lugar, a de que, em nosso presente, em termos amplos, tanto o governo como o controle das subjetividades e das condutas infantis, seja das referentes à infância pobre (infância excluída), seja das referentes à infância de origem pequeno-burguesa, característica das classes média e média-alta dos países desenvolvidos e emergentes (infância incluída), são efetuados mediante a estratégia de um empresariamento generalizado da sociedade e da educação. As sociedades contemporâneas, animadas por um novo capitalismo, de tipo conexionista, transnacional e financeiro, assumem uma dupla face, expressando-se simultaneamente como sociedades de controle (cf. Deleuze, 1992) e como sociedades-empresa (cf. Foucault, 2008). Por um lado, o controle e o governo das condutas dos indivíduos dão-se cada vez mais por intermédio de um empresariamento da sociedade; por outro, o empresariamento das subjetividades e das relações sociais constitui como que a via privilegiada para o controle e o governo das condutas. Assim, em termos amplos, podemos pensar o governo das infâncias em nosso presente como estando estreitamente relacionado ao empresariamento da sociedade, da educação e dos demais processos implicados à produção de subjetividades infantis (modos de construção do que seria "ser criança").

Em segundo lugar, trata-se de seguir e explorar a ideia de que, no caso da infância pobre (excluída), seu governo e seu controle se exercitam primordialmente através de políticas, programas e/ ou projetos assistenciais, socioeducativos e culturais de orientação eminentemente biopolítica, os quais funcionam em estreita sintonia com essa tendência a um empresariamento generalizado da sociedade e da educação. Minha exposição será feita em dois momentos interligados. No primeiro deles, mais longo e de cunho teórico, tentarei caracterizar a estreita relação entre governamentalidade neoliberal e "empresariamento da sociedade"; no segundo, por seu turno, tentarei oferecer algumas sinalizações sobre como se deu e sobre como vêm se dando, em nosso presente, o governo da infância pobre, ou da infância excluída. Neste último caso, cabe assinalar que minhas considerações, 
sem que se pretendam exaustivas, limitar-se-ão a aspectos de ordem macro, vinculados, dentro do possível, ao essencial da programática de ação da governamentalidade neoliberal, sobretudo tal como desenvolvida nos/pelos EUA.

\section{Governamentalidade neoliberal \\ e empresariamento da sociedade}

Em que sentido, em nossos dias, governo e controle podem ser entendidos como uma questão de empresariamento da sociedade como um todo e, para o que nos interessa mais de perto, da assistência e educação da infância referente aos extratos mais pobres e desprivilegiados da população? Para tentar responder a essa pergunta, seguirei basicamente as sinalizações indicadas por Foucault em Nascimento da biopolítica (2008b).

Para Foucault (2008), o grande desafio de uma arte de governar neoliberal era saber se uma economia de mercado podia servir de princípio, forma ou modelo para o funcionamento do Estado. Já não se tratava de pensar o Estado como instância que deveria vigiar o mercado, mas, inversamente, de fazer com que o mercado se tornasse o princípio organizador e formalizador do Estado e, ao mesmo tempo, seu vigia. Esse desafio foi posto à prova pelos neoliberais e terminou por operar deslocamentos tanto no papel e na função do Estado como no ponto de aplicação de suas intervenções. Assim, em prejuízo do mecanismo da troca, deu-se primazia ao mecanismo de concorrência, e foi justamente este mecanismo concorrencial, somado à ideia de liberdade econômica e ao imperativo da não-intervenção estatal na economia, que acabou por formalizar e organizar, desde então, tanto o funcionamento do Estado como o novo ponto de aplicação de suas intervenções: a sociedade. A partir dessa inflexão, a intervenção estatal na sociedade deu-se por intermédio da formalização desta pelo mecanismo da concorrência e pela disseminação da forma-empresa pelo tecido social, da maneira a mais extensa possível.

Todavia, esse primeiro movimento supunha outro, que consistia em não mais conceber o mecanismo de concorrência como um dado natural, espontâneo e, como lembra Foucault (2008b, p. 163), associado a um "jogo natural entre indivíduos e comportamentos"; tratava-se, diversamente, de assumi-lo como uma espécie de essência, uma entidade puramente formal que, doravante, complementa o filósofo (2008, p. 163), deveria remeter a um "jogo formal entre desigualdades". Nesses termos, na medida em que esse mecanismo concorrencial passou a ser concebido como devendo constituir apenas e tão somente um objetivo, ele, por conseguinte, para ser alcançado, passou a supor uma política infinitamente ativa. Para lograr êxito nesse imperativo de produzir 
e estimular a concorrência, foi necessária, pois, uma governamentalidade hiperativa, capaz de justapor totalmente as políticas governamentais aos mecanismos de mercado indexados pelo próprio mecanismo de concorrência. Isso quer dizer, por outro lado, que o Estado passou a atuar, a intervir, a funcionar não só sob uma lógica de mercado, uma lógica eminentemente empresarial, mas para o mercado. Ora, tal processo não é senão um processo de empresariamento do Estado e, consequentemente, de sua nova política de sociedade, ${ }^{2}$ política esta que terminou por submeter a própria sociedade a um empresariamento generalizado.

No caso dos ordoliberais alemães, esse movimento de disseminação (por multiplicação e diferenciação) da forma-empresa por toda a sociedade certamente foi levado a cabo; todavia ele o foi agregando preocupações morais e medidas que pudessem contrabalançar a frieza e a crueldade da concorrência econômica. Com efeito, a "economia social de mercado" alemã ainda buscava zelar por certo ethos comunitarista, ainda tentava preservar em seu funcionamento o que seria uma ética social da empresa (Sombart). Já no caso no anarcocapitalismo estadunidense, tais pruridos foram deixados de lado e todos os esforços apontaram na direção de fazer com que cada indivíduo, funcionando como uma empresa e como empresário de si, garantisse por sua própria conta sua inclusão e sustentação sociais. A teoria do Capital Humano, criada por Theodore Schultz, e desenvolvida por ele e outros colegas economistas da Escola de Chicago, como Becker e Stigler, não só serviu de matriz teórica para definir o estatuto do novo homo oeconomicus, como também influiu consideravelmente no tipo de política de sociedade, (programação ambiental) que passou a ter vigência no neoliberalismo. Antes de examinarmos o estatuto desse novo homo oeconomicus, e em que consiste essa política e/ou programação ambiental, tratemos rapidamente da teoria do Capital Humano.

A noção de capital humano, ou capital intelectual, refere-se a um conjunto de capacidades, habilidades e destrezas criadas, desenvolvidas, aperfeiçoadas e acumuladas pelos indivíduos, ao longo de suas existências. Uma vez que poucas dessas aptidões ou competências são herdadas geneticamente, a maior parte delas se deve a investimentos realizados em educação, seja pelos progenitores, seja pelos próprios indivíduos. Tal noção supõe, 
por outro lado, uma nova maneira de se conceber a noção de trabalho, pois este, desde as formulações desses economistas da escola de Chicago, passa a ser entendido como aquilo que é necessário para que o indivíduo possua uma renda, um salário. Ora, uma vez que para eles o trabalho comporta um capital, uma "máquina-competência", ou seja, o que estamos designando aqui por "capital humano", o salário constitui justamente a renda conseguida pelo investimento nesse capital intelectual. Mas, além disso, há que se acrescentar que esse trabalho e os investimentos em capital que the correspondem passam a ser considerados a partir do ponto de vista do próprio indivíduo-trabalhador, razão pela qual sua conduta; seu modo de agir; seu cálculo da relação custo-benefício de optar por investir em uma coisa, e não em outra; em suma, a forma como os indivíduos investem em seus respectivos capitais humanos, serão, doravante, o principal objeto da economia. Aliás, a ideia de que a economia tem por objeto o comportamento humano (entendido como conduta econômica), como veremos adiante, acena com fortes ressonâncias que passam a existir entre essa ciência econômica neoliberal estadunidense desenvolvida pela Escola de Chicago e o sistema psicológico conhecido como behaviorismo. Ressonâncias estas que ganham maior visibilidade ao se atentar, por exemplo, para o tipo de programação ambiental ou social preconizado por um radical como Gary Becker. De todo modo, é assim que, para Foucault (2008b, p. 311), o indivíduo contemporâneo deixa de ser considerado como parceiro de trocas econômicas (sociedade de consumo) e passa a ser considerado como um "empresário de si mesmo, sendo ele próprio seu capital, sendo para si mesmo seu produtor, sendo para si mesmo a fonte de [sua] renda".

A teoria do Capital Humano é crucial para o empresariamento da sociedade, pois parte significativa desse amplo, complexo e multifacetado processo, estreitamente ligado à construção de um novo espírito do capitalismo (cf. Boltanski e ChiapeIlo, 2009), à globalização e à consequente despadronização, flexibilização e precarização do mundo do trabalho, se expressa através de um dos principais desdobramentos daquela teoria, a saber: a difusão de uma cultura do empreendedorismo. Dentre os vários sentidos desse termo, "empreendedorismo", creio que merece especial destaque aquele que o concebe como uma "visão de mundo"; como um modo "de ser, de estar e de situar-se" em face da realidade e de outrem; em suma, como uma espécie de estilo de vida - que envolve, inclusive, uma relação a si o qual, para todos os efeitos, se deve adotar como imperativo.

A visão de mundo aí preconizada é uma visão eminente empresarial, movida pela concorrência e pela busca do sucesso; uma visão, pois, encarnada pelas figuras dos executivos das transnacionais (cf. 
López-Ruiz, 2007), os seja, desses modelos exemplares de que chamo "indivíduos micro-empresa" ("Você $S / A$ "). Os valores que servem de referência a esse modo "de ser, de estar e de situar$\mathrm{se}^{\prime \prime}$ em face da realidade e de outrem, também são oriundos de um ethos eminentemente empresarial, São eles: a "eficácia", a "eficiência", a "inovação", a "flexibilidade", a "iniciativa" (ser "pró-ativo"), a "criatividade", a "disposição em assumir riscos" etc. Por fim, o "estilo de vida" a ser adotado equivale a conceber e a assumir questões existenciais e relativas à vida cotidiana como se fossem questões empresariais. Por isso, em se tratando de como conduzir-se na vida, no trabalho, na família, dentre outros, dá-se desmedida importância, de um lado, às prescrições das teorias da gestão (management) e das tecnologias gerenciais e, de outro, às orientações provenientes da literatura de autoajuda relacionada às primeiras. Um bom empreendedor é um bom investidor em capital humano. É por esse motivo que a apologia do empreendedorismo e dos saberes e práticas do management, amiúde articulando o primeiro aos segundos, alastra-se por todos os domínios da vida social, inclusive na formação familiar e na educação formal proporcionada às crianças e aos jovens, se bem que de formas distinta, de acordo com a infância e a adolescência em questão.

Dito isto, podemos agora voltar ao estatuto do novo homo oeconomicus e à programação ambiental preconizada pela governamentalidade neoliberal. Leon Fahri Neto (2010, p. 177) esclarece bem tanto um como a outra, e busca articulá-los, conforme comparecem na analítica de Foucault:

A identificação sem restos do comportamento social com o comportamento econômico, a utilização da lógica de mercado, como princípio de inteligibilidade de todo e qualquer comportamento social, conduz uma certa vertente do neoliberalismo americano, talvez a mais radical, na direção de um behaviorismo econômico, segundo o qual o comportamento individual é controlável a partir da manipulação de variáveis econômicas. Toda conduta individual, que responde de forma sistemática a modificações nas variáveis do meio, sendo esse meio entendido como o mercado, como a realidade econômica, deve referir-se a uma análise de tipo econômico. $\mathrm{O}$ indivíduo funciona como sujeito econômico a partir do momento em que aceita o real, a situação de mercado em 
que está inserido, como determinante de sua conduta. O homo oeconomicus é aquele indivíduo que aceita regular suas ações em função das possibilidades que the são ofertadas pela realidade, fundamentalmente econômica. Assim, “[...] a economia vai poder se definir como a ciência da sistematicidade das respostas às variáveis do meio". O homo oeconomicus é o homem governável, desde que o governo utilize e manipule as variáveis econômicas para tanto ${ }^{3}$.

Depreende-se daí o motivo pelo qual Foucault associa essa governamentalidade neoliberal a uma espécie de behaviorismo econômico. No behaviorismo radical de Skinner, as noções de controle e governo, em linhas gerais, estão estreitamente associadas à constituição de agências controladoras que operam indiretamente sobre as condutas humanas, mediante a manipulação de variáveis ambientais. Partindo do pressuposto de que o comportamento humano perfaz uma variável dependente observável, e de que esta

\footnotetext{
3 As aspas referem-se a uma pequena citação que o autor faz de Foucault. Por outro lado, essa concepção foucaultiana do novo homo oeconomicus neoliberal, aproxima-se da de Michael Apple (2005, p. 37), para quem ele é um "homem manipulável (...), continuamente encorajado a ser responsivo perpetuamente".
}

variável, por sua vez, é sempre controlada por variáveis independentes, presentes ou potencialmente identificáveis, Skinner denominou as principais dessas variáveis controladoras de contingências de reforço. Como explica Kester Carrara (2005, p. 290), estas são “(...) consequências de respostas operantes que retroagem sobre o organismo, alterando a probabilidade de emissão futura dessa classe de respostas por esse organismo (...); contingências essas que podem ser naturalmente providas pelo ambiente físico ou histórico, culturalmente dispostas por ambientes sociais específicos." Tais contingências reforçadoras intervêm tanto nas relações entre duas pessoas, como nas relações grupais. Por outro lado, nos casos em que se constatam problemas ou deficiências nos controles pessoal e/ou grupal, acrescenta Carrara (2005, p.290), "certas agências controladoras melhor organizadas - como governo, religião, psicoterapia, economia e educação - manipulam variáveis específicas mais complexas, conseguindo assim operar com maior sucesso" ${ }^{\prime 4}$. Nesses

\footnotetext{
4 Sigrid Glenn (1986), em sua leitura da utopia ficcional de Skinner, Walden Two, busca fazer uma distinção entre, de um lado, contingências, aplicadas ao comportamento operante, e, de outro, metacontingências, aplicadas à cultura. Para a autora (1986, p. 2), metacontingência "é a unidade de análise que descreve as relações funcionais entre uma classe de operantes, cada operante tendo sua própria consequência, única e imediata, e uma consequência comum de longo prazo para todos os operantes da metacontingência. Metacontingências devem ser mediadas por contingências de reforçamento socialmente arranjadas. Tome, como exemplo, os vários comportamentos na produção da consequência atrasada de redução da poluição do ar. Os engenheiros precisam
} 
termos, grosso modo, poder-se-ia dizer que o comportamento humano (variável dependente), aos olhos dos economistas da escola de Chicago, equivale à conduta econômica, seja ela racional ou irracional; poder-se-ia dizer, além disso, que se tomarmos, dentre outros, a concorrência, o investimento em capital humano e a adoção e veneração dos saberes e tecnologias de gestão (o empreendedorismo) como referências fundamentais para a condução de condutas, todos esses fatores operam como contingências reforçadoras (variáveis independentes) necessárias ao condicionamento indireto das condutas dos indivíduos. Contingências reforçadoras, além disso, que operam através da programação e do controle das variáveis do meio em que vivem tais indivíduos; por fim, poder-se-ia dizer que, em termos concretos, as agências controladoras de que fala Carrara são todas as organizações, multilaterais ou nacionais, e todas as políticas, programas e projetos, governamentais e não-governamentais, que, voltando suas ações para o cuidado, assistência, proteção e educação de crianças pobres, passaram a funcionar segundo o modelo da forma-empresa, supervalorizando a concorrência e a capitalização de sua "clientela", enaltecendo e assimilando ao seu funcionamento as novas tecnologias de gestão, a cultura do politicamente correto, o desenvolvimento sustentável, a sensibilidade "ao social" e, sobretudo, o culto ao empreendedorismo.

Tomando o que foi dito até aqui como referência, passemos agora a uma sumária e sucinta caracterização de como a "infância pobre", a que me referi anteriormente, foi e vem sendo governada.

\section{O governo da infância excluída}

No período colonial, sob o jugo dos jesuítas, as crianças indígenas foram cristianizadas e disciplinarizadas de maneira metódica, o que permitiu que os padres da Companhia de Jesus também estendessem suas práticas civilizatórias aos índios adultos, convertendo-os, como diz Rizzini y Pilotti (2009, p. 17), "às estruturas sociais e culturais recém-importadas." No mesmo período histórico, mas agora em outro registro, temos as crianças negras e 
escravas, sob a responsabilidade dos Senhores de engenho e de seus capatazes. Quanto à regulamentação de matérias referentes aos escravos e aos filhos destes, segundo Rizzini e Pilotti (2009), isso só aconteceria na legislação a partir dos anos 1850. Sobressai-se, a esse respeito, a Lei n. 2040, de 28 de setembro de 1871, conhecida como Lei "do ventre livre", a qual declarava livres os filhos de mulheres escravas, nascidos após a promulgação dessa Lei, e que, dentre outras providências, deliberava sobre a criação e o tratamento a serem dados aos menores. Nesse particular, ainda de acordo com Rizzini e Pilotti (2009, p. 103), a Lei "estipulava obrigações para os senhores dos escravos e para o governo no tocante à criação dos filhos menores, proibindo que separassem os filhos menores de 12 anos do pai ou da mãe e prevendo formas de recolhimento para aqueles que fossem abandonados." Todavia, ponderam os autores (2009, pp. 103-104), a liberdade desses filhos menores era relativa, pois "permanecia condicionada à vontade do Senhor, à medida em que este, ao 'criá-los' até os 8 anos de idade, adquiria o direito de usufruir de seu trabalho até que completassem 21 anos, ou então entregá-los ao Estado, recebendo, neste caso, uma indenização."

Principalmente a partir da segunda metade do século XIX, assiste-se à ascensão "do social" no Brasil, entendido tanto como campo de intervenção de biopoderes quanto como rede de práticas, saberes e instituições que formam como que um dispositivo biopolítico de segurança, responsável pela gestão, policiamento e regulamentação da vida das populações pobres. Essa rede discursiva e institucional envolvia saberes como os da medicina social, da psiquiatria e da puericultura, saberes jurídico-criminológicos, instituições caritativo-religiosas de encerramento, como os asilos de órfãos, abandonados ou desvalidos; órgãos governamentais de assistência e responsáveis pela segurança, tais como as câmaras municipais, a polícia e o juízo de menores; instituições filantrópicas como a Santa Casa de Misericórdia - onde se implantou o "sistema da roda" - e; mais tardiamente, logo no início do século $X X$, os institutos de proteção e assistência à infância, cuja prática, eminentemente higienista, orientava-se, em termos, mais pelo cientificismo do que por uma perspectiva estritamente moral e religiosa.

Desde meados do século XIX, o estatuto da infância pobre, sobretudo das crianças negras e índias, era negativado pelas práticas filantrópicas e, depois, já nas primeiras décadas do século $X X$, pelos discursos psicopedagógicos, médico -higienistas e pelos princípios que guiavam as ações dos reformadores. Essa negativação, segundo César (2008), começou na verdade atingindo as famílias das crianças pobres, fossem elas operárias, ou não; em todo caso, tais famílias eram consideradas "disfuncionais", haja vista que, para além de sua situação 
periclitante, em termos materiais, eram tidas como incapazes, moral e intelectualmente, de fornecer os devidos cuidados e a atenção julgada necessária para a boa formação e o bom desenvolvimento das crianças e dos adolescentes. Nesse sentido, as crianças e, sobretudo, os adolescentes pertencentes às famílias pobres e operárias, vistos como estando em situação de abandono, de risco, de vulnerabilidade, concebidos como prisioneiros de um círculo vicioso de privação/depravação, e uma vez encarnando essa ingrata condição, justificaram a montagem de todo um aparato psicopedagógico, médico-social, corretivo e segregacionista, consubstanciando em alguns aspectos aquilo a que Michel Foucault chamou de biopolítica.

No Brasil, a infâmia dessas famílias pobres e de suas crianças e adolescentes associava-se, ainda: a) ao racismo e a outros elementos ligados à herança maldita da escravidão; b) aos efeitos perversos do analfabetismo; c) à desqualificação, estigmatização e criminalização desses personagens, promovidas pela psiquiatria, pelas teorias eugenistas e pelas práticas médico-sanitaristas e jurídico-policiais. ${ }^{5}$ Quero enfatizar, com isso, que a história da família, da infância e da adolescência pobres, no Brasil, antes e no decorrer de todo o longo século XX, foi marcada pela estigmatização, marginalização, exclusão e criminalização (implicando, de acordo com os discursos que então dominavam o campo "do social", particularmente no que respeita às crianças e aos adolescentes, uma série que ia do ócio à delinquência, passando pela vadiagem e pela libertinagem). Com o advento do Estado Novo, as vidas de tais famílias e de suas crianças e adolescentes seriam disciplinarizadas, normalizadas e regulamentadas estrategicamente por biopolíticas que visavam, dentre outras coisas: produzir um sentimento de unidade e uma identidade nacional para os brasileiros; unificar e padronizar o sistema de ensino, para melhor educar a população; erguer um sistema previdenciário; estabelecer as condições necessárias à modernização e ao desenvolvimento e industrialização do País - para o que também foi necessário incrementar o ensino técnico-profissional (SESC, SESI SENAI); produzir, por fim, um aparato correcional-repressivo destinado a atender aos menores abandonados e àqueles que cometeram atos infracionais. Nos anos 1940, tal concepção de atendimento é encarnada pelo SAM (Serviço 
de Assistência ao Menor), ao passo que, logo após a instauração da ditadura militar, tal aparato se mantém vivo nos quadros do sistema FUNABEM-FEBEMs, em que segregação, autoritarismo e assistencialismo se mesclam de forma impressionante. Daquela época até meados dos anos 1970, os horrores perpetrados por esse aparato correcional-repressivo ganham visibilidade, uma vez associados à escalada de violência nas grandes cidades, às grandes rebeliões em unidades das FEBEMs, às desigualdades sociais brasileiras e à dramatização da "questão do menor", cada vez mais presente na pauta dos meios de comunicação de massa. Em linhas gerais, as famílias pobres e suas crianças foram assistidas por políticas assistenciais compensatórias que seguiam remotamente, bem ou mal, o espírito do pacto keynesiano entre capital e trabalho.

Todavia, com a globalização, com o advento do novo capitalismo, transnacional e financeiro, com o neoliberalismo e com o consequente desmonte de tudo o que até então padronizava o mundo do trabalho - desregulamentação, flexibilização, precarização do trabaIho, abandono da política de pleno emprego etc. -, observamos que as populações pobres terminaram por ficar numa situação extremamente fragilizada. A julgar pelas considerações feitas por Robert Castel (2000; 2005) acerca das transformações questão social e da insegurança social daí advinda, acredito que a difusão de uma cultura do empreendedorismo pode ser entendida como uma maneira perversa e cínica de o sistema sugerir, aos indivíduos e às coletividades pobres, que, num momento em que os sindicatos e as associações classistas se encontravam enfraquecidos, senão esvaziados; em que o Estado providência mais parecia coisa do passado; em que o outro passava a constituir um obstáculo a ser batido - haja vista ser um concorrente -, todos, desde então, deveriam ficar por sua própria conta e risco. Tudo isso sugerido em meio a uma atmosfera marcada pela incerteza, na qual a insegurança, o risco do desemprego crônico e a falta de perspectivas para o futuro pairavam permanentemente sobre os ombros dos indivíduos, como espectros sinistros. Ao mesmo tempo, por efeito mesmo da insegurança assim disseminada, o neoliberalismo tornava esses dois estratos populacionais (infâncias e famílias pobres) mais suscetíveis de aderirem ou se submeterem às suas estratégias de governo, controle e assujeitamento.

Seria oportuno, neste momento, tentar descrever, mesmo que sucintamente, o modo como os anarcoliberais estadunidenses pensavam o governo da pobreza em sua política de sociedade, ou em sua "política ambiental". Para ir direto ao assunto, recorro a um trecho esclarecedor da ótima tese de doutorado de Viviane Klaus (2011, p. 165), francamente alinhada às formulações de Foucault acerca do neoliberalismo, 
e intitulada Governamentalidade (neo)liberal: da administração à gestão educacional:

Numa lógica que prima pela concorrência, a escassez não é um problema porque não está em jogo a extinção da pobreza, mas o seu abrandamento. Dentro dessa lógica, a pobreza não pode ser absoluta, mas relativa. A pobreza absoluta deve ser gerenciada - uma vez que as pessoas precisam participar do jogo, possuir um patamar mínimo de consumo e integrar as malhas do poder -, e a pobreza relativa passa ser uma condição quase inevitável. Isso se dá porque um dos princípios do neoliberalismo é o de que a economia deve ter seus objetivos próprios, porém, devem ser descolados de tal modo que o processo econômico não seja comprometido ou perturbado pelos mecanismos sociais.

Situemos melhor as coisas. Políticas econômicas e sociais que promovam efetivamente uma real redistribuição de renda e diminuam substancialmente as desigualdades sociais entre ricos e pobres - como querem não só os setores progressistas da sociedade brasileira, mas também a literatura alinhada à tradição crítico-socialista e os movimentos sociais -, tudo isso contraria abertamente esse princípio neoliberal. Lembremos que, para os neoliberais, a pobreza relativa é um dado inexorável, ao passo que a existência de desigualdades constitui um pressuposto ao funcionamento do sistema e da nova arte de governar. Tendo isso em vista, e na esteira dessa dissociação entre o econômico e o social, a governamentalidade neoliberal estadunidense irá formular, diz Foucault (2008b, p. 277), o princípio (também presente no ordoliberalismo alemão e no neoliberalismo francês), de que "a economia é essencialmente um jogo, que a economia se desenvolve como um jogo entre parceiros, que a sociedade inteira deve ser permeada por esse jogo econômico, e que o Estado tem por função essencial definir as regras econômicas do jogo e garantir que sejam efetivamente bem aplicadas." Todavia, dentre as regras que fazem com que esse jogo seja o mais ativo possível, envolvendo (beneficiando?), portanto, um maior número de indivíduos, uma em particular mostra-se capital, e ela sinaliza com a impossibilidade de que um dos jogadores perca tudo e, consequentemente, veja-se impossibilitado de continuar no jogo. Assim, o objetivo desta regra é salvaguardar o jogador que porventura venha a se encontrar nessa condição; ela pode, sim, limitar seus movimentos, contanto - e 
isso é fundamental - que não interfira no desenrolar do jogo. Pois bem, é com base na dissociação entre o social e o econômico, de um lado, e com base no princípio acima descrito, de outro, que os economistas de Escola de Chicago desenvolveram a ideia do imposto negativo, definido por Foucault (2008b, p. 280) nos seguintes termos:

O que é o imposto negativo? Para resumir as coisas muito simplesmente mesmo, podemos dizer que a ideia do imposto negativo é a seguinte: um benefício social, para ser socialmente eficaz sem ser economicamente perturbador, não deve nunca, na medida do possível, se apresentar sob a forma de consumo coletivo, porque, dizem os partidários do imposto negativo, a experiência prova que quem dele tira proveito são os mais ricos, e tiram proveito sendo quem menos participa do seu financiamento. Logo, se se quer ter uma proteção social eficaz, sem incidência econômica negativa, há simplesmente que substituir todos esses financiamentos globais, todos esses subsídios mais ou menos categoriais, por um subsídio que seria em espécie e proporcionaria recursos complementares a quem, e somente a quem, a título definitivo ou a título provisório, não alcança um patamar suficiente. Falando bem claramente, digamos que não vale a pena dar às pessoas mais ricas a possibilidade de participar do consumo coletivo da saúde; elas podem perfeitamente garantir sua própria saúde. Em compensação, vocês têm na sociedade uma categoria de indivíduos que, seja a título definitivo, por serem idosos ou deficientes, seja a título provisório, por terem perdido o emprego, por serem desempregados, não podem alcançar um certo patamar de consumo que a sociedade considera decente. Pois bem, é para eles e em favor deles exclusivamente que se deveria atribuir o que constitui os benefícios compensatórios, os benefícios de cobertura característicos de uma política social. Por conseguinte, abaixo de certo nível de renda será pago certo complemento, ainda que, evidentemente, se tenha de abandonar a ideia de que a sociedade inteira deve a cada um de seus 
membros serviços como a saúde ou a educação, ainda também - e é esse, sem dúvida, o elemento mais importante - que se tenha de reintroduzir uma distorção entre os pobres e os outros, os assistidos e os não-assistidos.

Sem que deva ser tomado em termos drásticos ou simplistas, como se poderia imaginar, o projeto do imposto negativo, embora nunca tenha sido de fato implantado na França, por exemplo, ${ }^{6}$ guarda, pelo menos virtualmente, certa sofisticação, pois, como frisa Foucault (2008b), demanda que as pessoas por ele eventualmente contempladas não tomem o recebimento do referido subsídio complementar como uma forma de vida que resolveria seus problemas de uma vez por todas. Demovendo-as, por exemplo, da ideia de continuarem a procurar trabalho e, assim, de reintroduzirem-se no jogo econômico. Conclui Foucault (2008b, p. 281):

Então, toda uma série de modulações, de gradações, faz que, por meio do imposto negativo, o indivíduo por um lado tenha garantido certo nível de consumo, mas com motivações suficientes ou, digamos, com frustrações suficientes para que ainda tenha vontade de trabalhar e seja sempre preferível trabalhar a receber um benefício.

Assim, como afirma Klaus (2011), em alusão a uma das observações finais feitas por Foucault a propósito do imposto negativo, o governo das famílias e da infância pobres passa pela constituição de uma população flutuante, uma espécie de reserva de mão-de-obra, que deve estar sempre virtualmente disponível, ou seja, em condições de empregabilidade, sempre que isso se fizer necessário, e desde que não venha a comprometer ou perturbar os processos econômicos; desde que não venha, portanto, a por em risco a única política social que de fato interessa aos anarcoliberais estadunidenses, a saber: o crescimento econômico.

Tendo isso em conta, a vida das crianças pobres, como que reduzidas à condição de zoé ("vida nua"), como diz Agamben (2002), passa a ser gerida por uma rede formada pelo ensino público, pelo atendimento assistencial e em saúde, e ainda por uma profusão de organizações do chamado terceiro setor; aliás, setor cada vez mais implicado em sérias polêmicas, haja vista que, salvo honrosas exceções, mais se assemelha a um verdadeiro

6 Como cogitaram Giscard D'Estaing e seu staff (Sttoléru e Stoffäes), na segunda metade nos anos 1970. Vale salientar, a propósito, que, no Brasil, o Programa Bolsa Família, do qual falarei mais adiante, é inspirado nessa ideia do imposto negativo: cf. Weissheimer (2006, pp. 26 a 34). 
balcão de negócios. Em todo caso, seja através da educação pública, seja por intermédio de programas e/ ou projetos sociais e em saúde coletiva, seja, ainda, através de iniciativas das ONGs, o atendimento e a assistência às crianças e aos adolescentes pobres se dão, de um lado, pelo viés do empresariamento social (ou seja, pela adoção de valores, princípios e tecnologias de gestão oriundos do mundo empresarial) e, de outro, por uma espécie de neo-humanismo que vê com demasiado otimismo as possibilidades abertas pelos direitos humanos (sobretudo, no que diz respeito à superação de graves, antigos e novos problemas referentes à infância excluída); ${ }^{7}$ neo-humanismo que, além disso, aposta muitas de suas fichas numa celebração fraca da diversidade, num militantismo de cunho eco-ambiental e, por fim, guarda uma orientação sobremaneira moralista, cuja expressão maior pode ser captada na difusão de uma cultura do politicamente correto. É assim que uma série de práticas discursivas

7 Esse otimismo é notório, por exemplo, nas lutas pela aprovação do Estatuto da Criança e do Adolescente. A inflexão importante a ser considerada, nesse sentido, verdadeira unanimidade e solidária ao processo de democratização que avançava no Brasil naquela época, era a de deixar de conceber a criança e o adolescente como objetos (do direito, da tutela do Estado, de outras intervenções etc.), para convertê-los ao estatuto de sujeitos, "recuperando" sua cidadania. Sem que se possa negar a importância dessas lutas e dos avanços conquistados no plano da legislação, não de pode esquecer que não se combate a norma disciplinar-normalizadora, tal como descrita e problematizada por Michel Foucault - sobretudo, em Vigiar e punir (1987) e em A vontade de saber (1999) -, recorrendo-se meramente à norma jurídica e aos mais nobres sentimentos de indignação diante das injustiças sociais. e não-discursivas entra em cena no campo (do) social, perfazendo uma rede em cujo emaranhado encontramos, por exemplo: a ideia de "educação permanente"; a ideia de que o importante é "aprender a aprender"; "pedagogias empreendedoras"; "pedagogias da competência"; pedagogias cidadãs, que clamam por maior autonomia, democracia, participação, "empoderamento" e responsabilização; "pedagogias ambientais", ou "da sustentabilidade", sensíveis ao que sucede a Gaia; "pedagogias multiculturalistas", tolerantes, sensíveis à alteridade e aos clamores por um "direito à diferença"; e "pedagogias inclusivas".

Um elemento curioso e recorrente nos saberes e valores que sustentam e animam essas novas práticas e pedagogias, e que diz respeito diretamente ao modo como se referem "à" infância (particularmente à infância das classes desprivilegiadas) e buscam atende-la, desde então, é que tudo se passa como se - após um estranho sono sócio-antropológico e/ou psicossociológico (lembrando Kant), - de repente, se dessem conta de que estavam como que surdos e/ ou indiferentes ante aos anseios, às expectativas, aos desejos, às percepções e às falas das crianças - como se nunca as tivessem coagido a falar de si, de seus desejos, medos, "pecados", culpas e "erros", mas também de seus irmãos, de seus pais, professores etc.). Talvez isso explique a mobilização geral em torno do novo imperativo: "É preciso escutar e dar vOz às crianças"! 
Pois bem, considerando tudo o que foi mencionado acima, que nova arte de governar se esboça no horizonte descortinado pelas análises de Foucault? Para ele (2008b, pp. 354-355):

(...) não é em absoluto o ideal ou o projeto de uma sociedade exaustivamente disciplinar em que a rede legal que encerra os indivíduos seria substituída e prolongada de dentro por mecanismos, digamos, normativos. Tampouco é uma sociedade em que o mecanismo da normalização geral e da exclusão do não- normalizável seria requerido. Tem-se, ao contrário, no horizonte disso, a imagem ou a ideia ou o tema-programa de uma sociedade na qual haveria otimização dos sistemas de diferença, em que o terreno ficaria livre para os processos oscilatórios, em que haveria uma tolerância concedida aos indivíduos e às práticas minoritárias, na qual haveria uma ação, não sobre os jogadores do jogo, mas sobre as regras do jogo, e, enfim, na qual haveria uma intervenção que não seria do tipo da sujeição interna dos indivíduos, mas uma intervenção de tipo ambiental.

Não é por outro motivo que, no Brasil, os movimentos minoritários que lutam pelos direitos dos excluídos, inclusive pelos das crianças, se vejam numa espécie de saia justa, suas ações sendo permeadas por ambiguidades e certa desorientação. Tais movimentos reclamam por maior autonomia, participação e democratização nas tomadas de decisão relativas, por exemplo, à definição de políticas públicas e de ações afirmativas para a saúde, a cultura e a educação. Ao que a governamentalidade neoliberal responde: "Ótimo, é perfeitamente possível se estabelecer um acordo em relação a tais pontos. Aliás, mais que um acordo. Estado, mercado e empresas querem tê-los como parceiros nessa caminhada para superar as desigualdades e conquistar o desenvolvimento sustentável para o país. Eles veem com simpatia as ideias de autogestão e de autonomização, pois não pretendem tutelar nem tampouco se responsabilizar pelos segmentos organizados da sociedade civil. Consideram, inclusive, que se fazem necessárias uma maior descentralização, flexibilização e modernização na gestão pública, na gestão das pessoas, bem como dos problemas diagnosticados nas áreas de educação, saúde, cultura e segurança; afinal, tudo é uma questão de gestão! Consideram, além disso, que não se pode realmente tratar de forma igualitária os que se encontram em condições desiguais, e por 
isso veem de bom grado não só o princípio de equidade, mas também o tão reivindicado "direito à diferença" e as lutas por ações afirmativas." De modo semelhante, não é sem razão que setores progressistas e/ou de esquerda não raro se vejam indecisos entre aplaudir ou criticar um Programa como o Bolsa-Família, ${ }^{8}$ pois, malgrado algumas de suas

8 Weissheimer (2006, pp. 25-26) nos dá uma descrição dos aspectos essenciais deste que é considerado o mais importante programa social do governo federal, tanto na anterior como na atual gestão do PT: "Instituído pela Medida Provisória n 132, em outubro de 2003, o Bolsa Família é um programa federal de transferência direta de renda destinado às famílias em situação de pobreza (renda mensal por pessoa de $R \$ 60,00$ a $R \$ 120,00$ ) e de extrema pobreza (com renda mensal por pessoa de até $\mathrm{R} \$ 60,00$ ). Uma das características do programa é que ele procura associar a transferência do benefício financeiro ao acesso a direitos sociais básicos, como saúde, alimentação, educação e assistência social. O Bolsa Família tem dois objetivos básicos: combater a miséria e a exclusão social, e promover a emancipação das famílias pobres. Uma das novidades do programa em relação a iniciativas similares anteriores foi a unificação de todos os benefícios sociais do governo federal (Bolsa Escola, Bolsa Alimentação, Cartão Alimentação e Auxílio Gás) em um único programa. O objetivo da unificação foi garantir maior agilidade na liberação do dinheiro, reduzir a burocracia e melhorar o controle dos recursos. O programa é gerido pelo Ministério de Desenvolvimento Social e Combate à Fome (MDS) em parceria com os estados e municípios. As prefeituras são responsáveis pelo cadastramento das famílias e pela atualização da base de dados do Cadastro Único. Além disso, devem acompanhar o cumprimento das condicionalidades do benefício, além de promover ações complementares destinadas ao desenvolvimento autônomo e sustentado das famílias pobres do município. Quais são essas condicionalidades? As famílias devem participar de aços no acompanhamento de saúde e do estado nutricional dos filhos, matricular e acompanhar a frequência escolar das crianças no ensino fundamental e participar de ações de educação alimentar.Com base nas informações do Cadastro Único elaborado pelas prefeituras, o MDS seleciona as famílias a serem beneficiadas. O controle social sobre o programa é exercido mediante a constituição de Comissões Municipais intersetoriais e conquistas e sua amplitude, talvez não passe de um arremedo de política social, eminentemente assistencialista e incapaz de se constituir como indutor de um efetivo desenvolvimento e de se contrapor de fato às desigualdades sociais existentes no país ${ }^{9}$. De outra parte, tais ambiguidades servem de pretexto para que certos intelectuais se apressem em desqualificar os movimentos minoritários que exercitam políticas da diferença, alegando que, em assim procedendo, não fazem mais do que jogar o jogo da direita. Ciladas armadas pela diferença, ou ciladas armadas para a diferença?

Um último tópico que gostaria de apreciar, diz respeito a outra faceta do empresariamento da sociedade, faceta esta que repercute de forma significativa no governo da infância pobre, inclusive no governo que se

paritárias. A Caixa Econômica Federal (CEF) é o agente operador do cadastro e do pagamento dos benefícios.

9 Segundo Weissheimer (2006), talvez a crítica mais consistente e equilibrada feita ao Bolsa Família tenha sido a do economista Guilherme Delgado, do IPEA, sintetizada por este (apud Weissheimer, 2006, p. 117) da seguinte forma: "O fato de ter melhorado a distribuição de renda pessoal não significa que melhorou a distribuição da renda social como um todo. Essa renda representa apenas 31\% da renda interna bruta. Os outros praticamente $70 \%$ são gerados nas empresas financeiras e nãofinanceiras, ou de administração pública, e o perfil dessa outra estrutura tem caráter de piora na distribuição. Isso acontece porque há uma concentração de rendimentos oriundos dos juros e dos lucros contra os rendimentos dos salários e ordenados. Então, melhora a distribuição de renda domiciliar, mas piora a distribuição funcional da renda, como nós chamamos, em linguagem econômica, ou seja, lucros e salários. Aquilo que melhora, melhora fundamentalmente não por conta dos salários, mas por conta das transferências constitucionais associadas aos direitos de cidadania" 
materializa pela educação. Trata-se aqui, como assinala Michael Apple (2005, p. 38), da ideia de que todos, inclusive as crianças, os professores, os supervisores, os coordenadores e os diretores das escolas em que aquelas estudam, todos têm de produzir ininterruptamente evidências de que estão "fazendo as coisas 'com eficiência' e da 'maneira correta'". Isso terminou por originar uma assustadora e estressante "cultura da auditoria" (audit culture), que Colin Leys (apud, Apple, 2005, p. 39) define nos seguintes termos:

Há uma proliferação de auditorias, isto é, o uso de conceitos derivados da área de negócios e de supervisão independente para medir e avaliar o desempenho por parte de agências e empregados públicos, de funcionários públicos e professores de escola, até de professores de universidade, e médicos: são auditorias de meio ambiente, de valor de dinheiro, gerencial, judicial, de dados, de propriedade intelectual, médica, de ensino e tecnologia, que surgiram e que, em diferentes graus de estabilidade institucional e de aceitação, deixaram pouquíssimas pessoas intocadas por esses desdobramentos.

No campo educacional, como aponta Veloso (2010, s/p.), tem sido cada vez mais corriqueiro a introdução de "mecanismos explícitos de recompensas e punições atrelados a metas educacionais, como a concessão de bônus para os professores de escolas que elevem o aprendizado de seus alunos." Essas práticas ou sistemas de responsabilização social, que tiveram origem nos Estados Unidos, vêm sendo adotados em outros países e, mais recentemente, institucionalizados entre nós. Com efeito, em 2007 criouse no Brasil um sistema de responsabilização nacional, mediante o qual foram estabelecidas metas de desempenho do IDEB (Índice de Desenvolvimento da Educação Básica) para cada uma das escolas públicas estaduais e para cada município do País, até o ano de 2021. São Paulo ("Programa de Qualidade na Escola" - 2008), Minas Gerais (Programa "Acordo de Resultados), Pernambuco ("Programa Bônus de Desempenho Educacional" - 2008), Rio de Janeiro ( na rede municipal de educação da capital, "Prova Rio" 2009) e Ceará ("Programa de Alfabetização na Idade Certa, PAIC - 2007, e PAIC MAIS - 2011) estão entre os Estados da federação que vêm implementando tais sistemas de responsabilização.

Como salienta Veloso (2010, s/p.), o conceito de responsabilização é central nas reformas que têm sido empreendidas: "A ideia 
é fazer com que os atores envolvidos no processo educacional sejam cobrados pelo desempenho dos alunos e, dessa forma, sejam criados incentivos para a melhoria do aprendizado. Uma maneira de fazer isso é através da divulgação pública das notas das escolas em exames padronizados, com o objetivo de gerar pressão por parte de pais e gestores sobre as escolas com piores resultados". Vemos aqui, pois, uma estratégia de governo e controle que funciona por modulação e pelo manejo de variáveis ambientais que terminam por induzir as condutas de crianças, pais, professores e demais agentes implicados à educação e aos cuidados da infância das classes populares.

"Quem quer ser um milionário?" Tal pergunta não pode ser levada a sério por aqueles que a proferem, quanto mais por aqueles que a escutam. Por quê? Porque, antes de tudo, ela sugere que as vidas das crianças tenderiam naturalmente para essa meta ou aspiração; em segundo lugar, porque se trata de um misto de indagação cínica e convite ao impossível: já se sabe de antemão que crianças pobres jamais se tornarão milionárias (as eventuais exceções só confirmariam a regra), não têm como sê-lo, senão no delírio extasiante de um programa de TV - num filme que, "apesar" de ruim e apelativo, terminou por conquistar o Oscar -, em que se joga com a vida como se numa loteria. Contudo, pouco ou quase nada parece impedir que as condutas e subjetividades de crianças pobres e excluídas sejam modificadas pela intervenção estratégica de condicionamentos ambientais que as induzam a buscar responder permanentemente a esse misto de indagação cínica e convite ao impossível, através de intermináveis investimentos em si mesmas, quer dizer, em seu capital humano, Nesses termos, governa-se a infância pobre, em nosso presente, fazendo com que o impossível torne-se, ao mesmo tempo, um imperativo incontornável.

\section{Referências bibliográficas}

Agamben, G. (2002). Homo sacer: o poder soberano e a vida nua I. Belo Horizonte: Editora UFMG. Apple, M. (2005). Para além da lógica do mercado: compreendendo-se e opondo-se ao neoliberalismo. Rio de Janeiro: DP\&A Editora.

Ariés, P. (1981). História social da criança e da família. Rio de Janeiro: Ed. Zahar.

Boltanski, L. e Chiapello, E. (2009). O novo espírito do capitalismo. São Paulo: Ed. Martins Fontes.

Buckingham, D. (2007). Crescer na era das mídias eletrônicas. São Paulo: Edições Loyola.

Bujes, M.I.E. (2002). Infância e maquinarias. Rio de Janeiro: DP\&A Editora.

Carrara, K. (2005). Behaviorismo radical: crítica e metacrítica. 2a. ed. São Paulo: Ed. UNESP.

César, M.R.A. (2008). A invenção da adolescência no discurso psicopedagógico. São Paulo: Editora UNESP. 
Castel, R. (2000a). As artimanhas da exclusão. Em: L.E. Wanderley e M.B. Wanderley. Desigualdade e a questão social (pp. 17-50). 2a. ed. São Paulo: EDUC.

Castel R. (2000b). As transformações da questão social. Em: L.E. Wanderley e M.B. Wanderley. Desigualdade e a questão social. Desigualdade e a questão social (pp. 235-264). 2a. ed. São Paulo: EDUC.

Castel, R. (2005). A insegurança social: o que é ser protegido? Petrópolis (RJ): Vozes.

Cohn, C. (2005). Antropologia da criança. Rio de Janeiro: Jorge Zahar Editor.

Deleuze, G. (1992). Post-scriptum sobre as sociedades de controle. Id. Conversações, 34, 219-226.

Diwan, P. (2007). Raça pura: uma história da Eugenia no Brasil e no mundo. São Paulo: Contexto.

Donzelot, J. (1980). A polícia das famílias. Rio de Janeiro: Ed. Graal.

Dornelles, L.V. (2005). Infâncias que nos escapam: da criança na rua à criança cyber. Petrópolis (RJ): Ed. Vozes.

Faria, A.L.G. e Finco, D. (orgs.). (2011). Sociologia da infância no Brasil. São Paulo: Ed. Autores Associados.

Foucault, M. (1987). Vigiar e punir: nascimento da prisão; tradução de Raquel Ramalhete. Petrópolis: Vozes.

Foucault, M. (1999). Historia da sexualidade. A vontade de saber. Rio de Janeiro: Edições Graal.

Foucault, M. (2008a). Segurança, território, população. Curso dado no Collège de France (1977-1978). São Paulo: Martins Fontes.

Foucault, M. (2008b). Nascimento da biopolítica. Curso dado no Collège de France (1978-1979). São Paulo: Martins Fontes.

Gadelha, S. (1998). Subjetividade e menor-idade: acompanhando o devir dos profissionais do social. São Paulo: Annablume.

Gadelha, S. (2009). Biopolítica, governamentalidade e educação: introdução e conexões a partir de Michel Foucault. Belo Horizonte: Autêntica.

Glenn, S.S. Metacontingencies in Walden Two. En: Behavior Analysis and Social Action 5 (1/2). Tradução de Thais Saglietti Meira Barros e revisão de Hélio José Guilhardi e Noreen Campbell de Aguirre (para uso dos grupos de estudo e supervisão do Instituto de Terapia por Contingências de Reforçamento). Campinas (SP). Disponível em: http://www.terapiaporcontingencias.com.br/pdf/outros/METACONTINGENCIAS_EM_ 
WALDEN_TWO.pdf. Acessado em 05/11/2011.

Gomes, A.M.R. (2008). Outras crianças, outras infâncias? In: Sarmento, M.; Gouvea, M.C.S. de Estudos da Infância: educação e práticas sociais. Petrópolis: Vozes, pp. 82-96.

Gouvea, M.C.S. (orgs.). Estudos da infância: educação e práticas sociais. 2a. ed. Petrópolis (RJ): Ed. Vozes.

Kuhlmann Jr., M. (2007). Infância e educação infantil: uma abordagem histórica. 4a. ed. Porto Alegre: Ed. Mediação.

Klaus, V. (2011). Governamentalidade (neo)liberal: da administração à gestão educacional. Tese de doutorado apresentada ao Programa de Pós-Graduação em Educação da UFRGS. Porto Alegre: UFRGS.

Lobo, L.F. (2008). Os infames da história: pobres, escravos e deficientes no Brasil. Rio de Janeiro: Lamparina.

López-Ruiz, O. (2007). Os executivos das transnacionais e o espírito do capitalismo: capital humano e empreendedorismo como valores sociais. Rio de Janeiro: Azougue Editorial.

Martins, P.C.M. (2009). Risco na infância: os contornos da evolução de um conceito. Em: M. Sarmento e Gouvea, M.C.S. (orgs.). Estudos da infância: educação e práticas sociais 246-271. 2a. ed. Petrópolis (RJ): Ed. Vozes.
Mota, A. (2003). Quem é bom já nasce feito: sanitarismo e eugenia no Brasil. Rio de Janeiro, DP\&A.

Neto, L.F. (2010). Biopolíticas: as formulações de Foucault. Florianópolis: Ed. Cidade Futura.

Rizzini, I. e Pilotti, F. (orgs.). (2009). $A$ arte de governar crianças: história das políticas sociais, da legislação e da assistência à infância no Brasil. 2a. ed. São Paulo: Cortez Editora.

Sarmento, M. (2009). Sociologia da infância: correntes e confluências. Em: M. Sarmento y M.C.S. Gouvea (orgs.). Estudos da infância: educação e práticas sociais 17-39. 2a. ed. Petrópolis (RJ): Ed. Vozes.

Sarmento, M. e Gouvea, M.C.S. (orgs.). (2009). Estudos da infância: educação e práticas sociais. 2a. ed. Petrópolis (RJ): Ed. Vozes.

Schwarcz, L.M. (2007). O espetáculo das raças: cientistas, instituições e questão racial no Brasil (1870 - 1930). 7a. Reimpressão. São Paulo: Companhia das Letras.

Veloso, F. Responsabilização em educação. Em: Folha de São Paulo (Mercado), 14/11/2010. Disponível em: http://www1. folha.uol.com.br/fsp/mercado/ me1311201020.htm. Acessado em 05/02/2011.

Weissheimer, M.A. (2006). Bolsa Família: avanços, limites e possibilidades do programa que está transformando a vida de milhões de milhões de famílias no Brasil. São Paulo: Editora da Fundação Perseu Abramo. 
